\title{
Physical Study Comparison of Neutral Red dye Prepared by Different Techniques for Low Dose Monitor Application
}

\section{E. Fahim and M. El-Kelany}

Radiation Protection and Dosimetry Dept., National Centre for Radiation Research and Technology (NCRRT), Egyptian Atomic Energy Authority, P. O. Box; 29 Nasr City, Egypt. ${ }^{\#}$ E.mail: dr.moosh@hotmail.com.

\footnotetext{
Tnvestigation of different preparation techniques related to $\mathrm{pH}$ indicator; Neutral Red (NR) dye indicates the effect of the substrate on the dose response. NR was incorporated in poly (vinyl alcohol) (PVA) to prepare a thin film dosimeter and added a gelatine to prepare gelatine gel dosimeter. Upon $\gamma$-ray exposure, both systems undergo visual red colour bleaching at $485 \mathrm{~nm}$ for the film and $480 \mathrm{~nm}$ for the gel at different rates depending on the sensitivity of each system. These two dosimetry systems depend mainly on the polymer substrate base. The useful dose range was up to $30 \mathrm{kGy}$ for thin film and 500Gy for gel form.

Keywords: Neutral red film, gel dosimeter, gamma-rays.
}

Many plastic films containing a radiation sensitive $\mathrm{pH}$ indicator dye with chloral hydrate have been prepared to be used as $\gamma$-radiation monitoring dosimeters and indicators (Abdel-Fattah and El-Kelany, 1998, Abdel-Fattah et al., 2002 and Soliman, 2005). These dyed plastic films undergo significant colour change upon exposure to $\gamma$-irradiation.

This change is related to the decomposition of chloral hydrate producing $\mathrm{H}^{+}$ion that induces a colour change of the $\mathrm{pH}$ indicator dye. A pervious study (Ebraheem et al., 2007), shows the effect of alanine on bromophenol blue polymeric films for radiation dosimetry applications. It also reveals that the dyed polymeric films prepared by a simple technique of casting an aqueous solution of PVA containing bromophenol blue on horizontal glass plate are useful for high dose dosimetry applications, and that the colour has a variable absorbance with applied dose in range from 1-35kGy. 

Dyed polymeric films, prepared by a simple technique of casting aqueous solutions of PVA containing Trypan blue (TB) dye, have been investigated and shown to be a useful dosimeter in the high dose applications. These films can be used as dosimeters in a relatively dose range up to 40kGy. On the other hand, these films are bleached when exposed to gamma rays (El- Kelany, 2011). The search for a dosimetry technique that allows full 3D imaging of a radiation dose distribution has led to the development of radiation-sensitive gels. These gels have a long history, with gel containing Folin's phenol, which change this colour upon irradiation.

\section{Experimental Work}

\section{Preparation of stock solution of $\mathrm{NR}\left(\mathrm{C}_{22} \mathrm{H}_{14} \mathrm{Br}_{4} \mathrm{O}_{4}-\mathrm{M} . \mathrm{W} .=661.96\right)$}

The stock solution of the indicator was prepared by dissolving $0.04 \mathrm{~g}$ of NR (Sigma-Aldrich, Inc., USA) in $25 \mathrm{ml}$ distilled water.

\section{Preparation of NR/PVA films}

Films were prepared by dissolving 10g of PVA powder (average M.W. 25,000 fully hydrolyzed 99-100\% product of J.T. Baker Chemical Co. USA) in $250 \mathrm{ml}$ doubly distilled water at about $60^{\circ} \mathrm{C}$. The solution was kept well stirred at the temperature for about $24 \mathrm{~h}$; then left to cool. To each $15 \mathrm{ml}$ of PVA solution $0.2,0.4$, and $0.5 \mathrm{phr}$ of dye stock solution were added and kept stirred for about $5 \mathrm{~h}$ at room temperature in order to obtain a uniformly dyed solution. The dyed PVA solutions were stirred, casted on a $10 \times 10 \mathrm{~cm}$ horizontal glass plate and dried at room temperature for about $48 \mathrm{~h}$. The film thickness was found to be $0.049 \pm$ $0.03 \mu \mathrm{m}, 1 \sigma$.

\section{Preparation of NR/ Gelatine gel dosimeter}

Three different concentrations of dye (3.44, 5.6 and $10.5 \mu \mathrm{mol} / \mathrm{L})$ and gelatine concentration of $20 \% \mathrm{w} / \mathrm{w}$ are chosen (that is, the mass of gelatine relative to the mass of the final gel). Gelatine was dissolved in distilled water and then the dye NR $\left(\mathrm{C}_{22} \mathrm{H}_{14} \mathrm{Br}_{4} \mathrm{O}_{4}\right)$ was added from a stock solution. The mixture was continuously stirred in a water bath. The solution turns to a pink colour. Since the reaction rate is dependent on temperature, the water bath was 
maintained at $70 \pm 5^{0} \mathrm{C}$ for $4 \mathrm{~h}$. This temperature was chosen for a fast colour change while keeping the temperature reasonably constant. Samples were pipette into $1 \mathrm{~cm}$ thickness glass test tube and immediately placed in a refrigerator at approximately $4^{0} \mathrm{C}$ for $4 \mathrm{~h}$.

\section{Instrumental analysis}

\section{Apparatus}

The absorption spectra of un-irradiated and irradiated films were measured in the wavelength range $200-800 \mathrm{~nm}$ using a UV4-visible spectrophotometer. Uvikon-860 spectrophotometer (KONTRON Co. Ltd., Switzerland) was used to measure the absorption spectra of the un-irradiated and irradiated samples.

The film thickness was measured using Digitrix-Mark-II thickness gauge (precision $\pm \mu \mathrm{m}$ ).

\section{Irradiation procedure}

Gamma-irradiations were carried out with a Gamma chamber $4000 \mathrm{~A}{ }^{60} \mathrm{Co}$ irradiation facility (BARC, India).

The absorbed dose rate in the irradiation facility was measured to be $1.471 \mathrm{kGy} / \mathrm{h}$ and the electronic equilibrium conditions were maintained during irradiation.

\section{Results and Discussion}

\section{Absorption spectra}

The absorption spectra of the un-irradiated and irradiated films and gels were measured in the wavelength range $300-800 \mathrm{~nm}$. The absorption spectra of the NR/ PVA films and gels ( $0.5 \mathrm{phr} \mathrm{NR})$ were recorded before and after irradiation to different doses as shown in Figs $(1,2)$. The absorption spectra of both systems show a main absorption band in the visible region characteristic of an orange colour peaking at $485 \mathrm{~nm}$ for film (Fig. 1), and at $480 \mathrm{~nm}$ for gel (Fig. 2). The amplitude of this peak decreases gradually with the increasing of absorbed dose of gamma ray photons. Also, it is shown that the gel system is more sensitive than the film system to $\gamma$-irradiation (note: same NR concentration).

Egypt. J. Rad. Sci. Applic., Vol. 29, No. 1-2 (2016) 


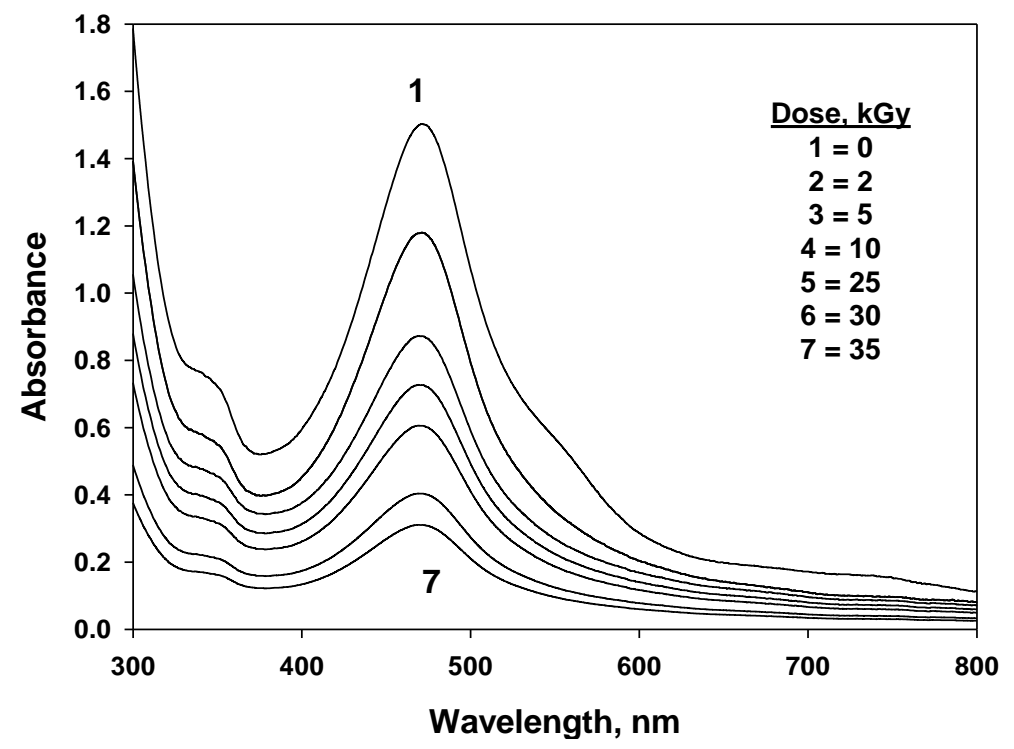

Fig. 1. The absorption spectra of NR film un-irradiated and irradiated to different absorbed doses. $[\mathrm{NR}]=0.5 \mathrm{phr}, \lambda_{\max }=485 \mathrm{~nm}$.

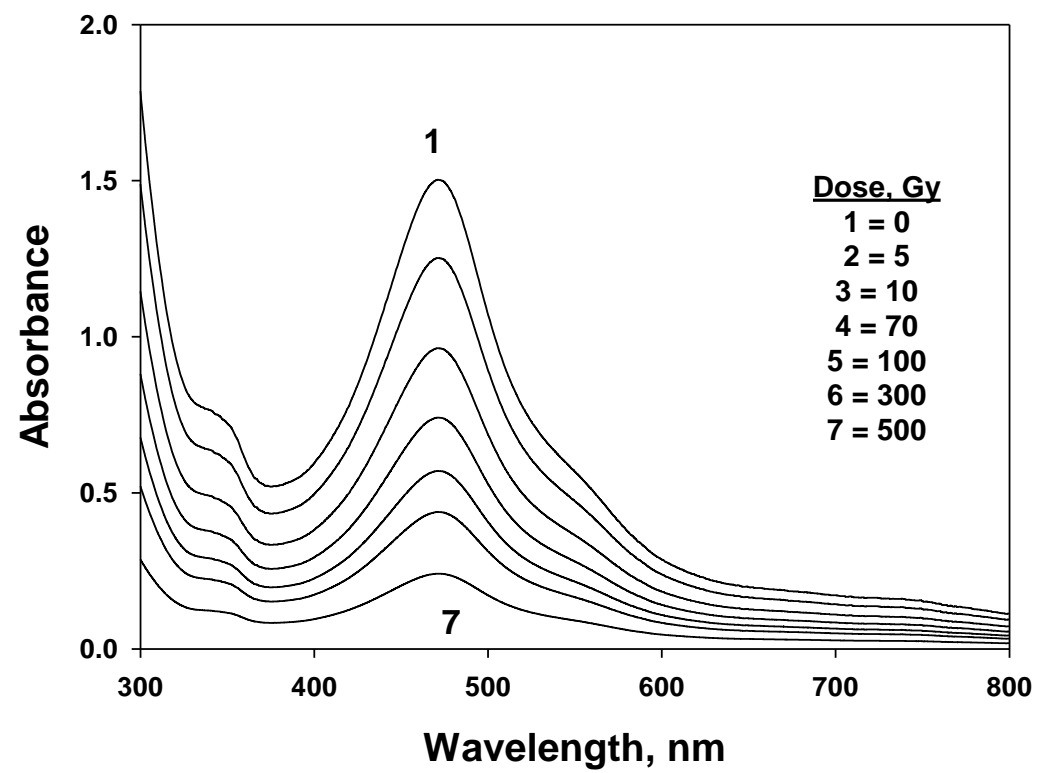

Fig. 2. The absorption spectra of the un-irradiated and gamma irradiated (NR gel) to different absorbed doses, $[\mathrm{NR}]=0.5 \mathrm{phr}, \lambda_{\max }=480 \mathrm{~nm}$.

Egypt. J. Rad. Sci. Applic., Vol. 29, No. 1-2 (2016) 


\section{Response curves}

A group of gel samples was irradiated in the range between 1 and 500Gy. Over that dose, the response tends to saturate. The resulting gel colour has an absorbance peak at $480 \mathrm{~nm}$, this peak bleaches upon irradiation as the gel bleaches. Fig. 3. shows the response curves of the dyed-gel samples with various NR concentrations. Each dose corresponds to three replicated test tube samples. The dose dependence is linear up to 350Gy.

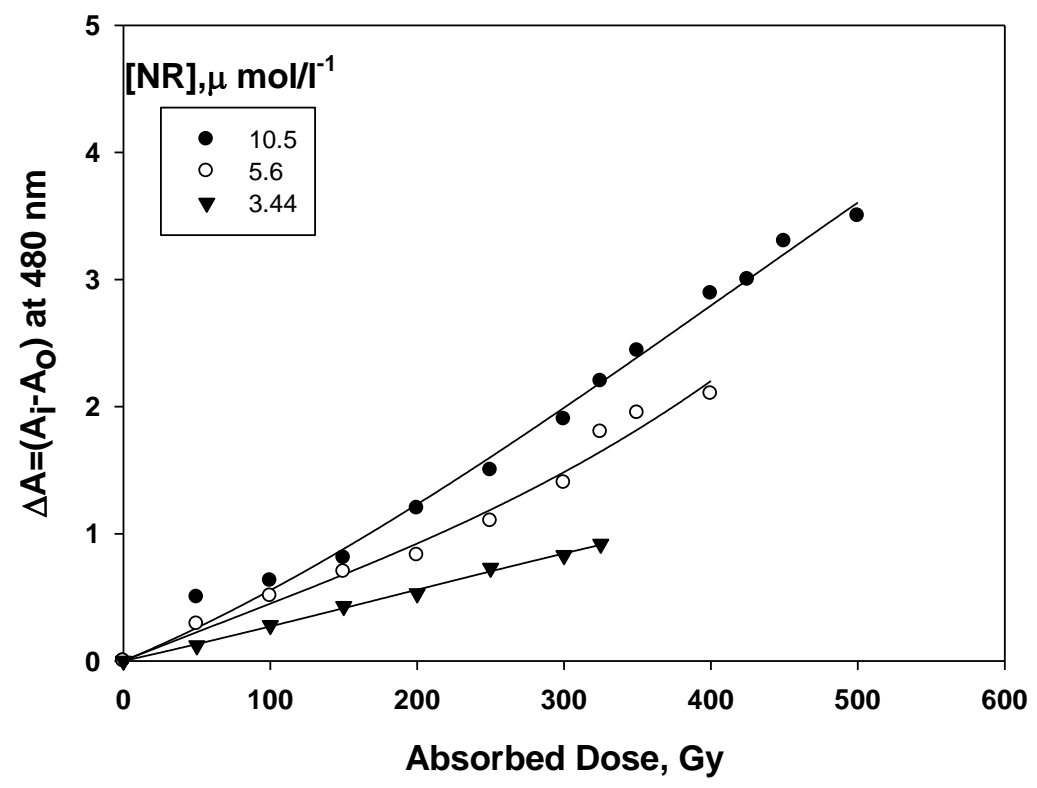

Fig. 3. Response curves of the (NR-gelatin) gel at $480 \mathrm{~nm}$ in the full dose range of 1500Gy.

On the other hand, Fig. 4. shows the response curves of film system at different concentrations of the dye $(0.2,0.4$ and $0.5 \mathrm{phr})$ in terms of change in absorption per unit thickness $\Delta \mathrm{A} . \mathrm{mm}^{-1}$ at $485 \mathrm{~nm}$, versus the absorbed dose, $\mathrm{D}$, where $\left(\Delta A=A_{o}-A_{i}\right)$ where $A_{o}$ and $A_{i}$ are values of absorption coefficient for the un-irradiated and irradiated films, respectively. The doses dependencies are linear up to $5 \mathrm{kGy}$, after this dose, the response take the curve shape till saturation at $\approx 30 \mathrm{kGy}$. 


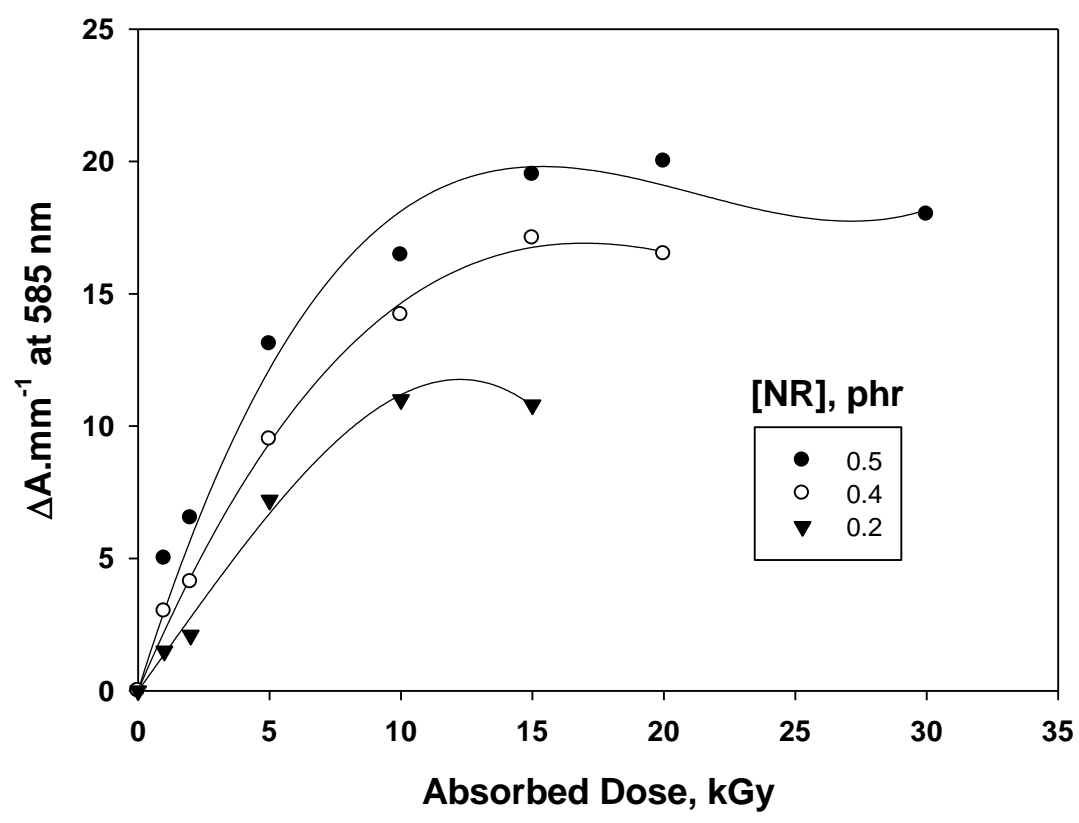

Fig. 4. Change of $\Delta A \cdot \mathrm{mm}^{-1}$, as a function of absorbed dose for different NR concentrations in PVA films, in the full dose range of 1-30kGy.

Both curves have the same behaviour towards the effect of radiation on dye concentrations. Increasing the absorbed dose accelerates the decomposing of lower dye concentration.

\section{Radiation chemical yield (G-Value)}

NR/PVA film

The radiation-chemical yield (G-value) is defined as the number of moles of dye degraded by the absorption of $1 \mathrm{~J}$ of energy (unit: $\mathrm{mol} / \mathrm{J}$ ). The G-value is calculated from the general relation.

$$
\mathrm{G}(\text { value })=\Delta \mathrm{A} / \text { D.e.p.b } \quad(\mathrm{mol} / \mathrm{J})
$$

where, $\Delta \mathrm{A}$ is the change in absorbance at $\lambda_{\max }, b$ is the optical path length $(1 \mathrm{~cm}), \varepsilon$ is the linear molar extinction coefficient for the solution at $\lambda_{\max }\left(\mathrm{Lmol}^{-1}\right.$ $\left.\mathrm{cm}^{-1}\right), \rho$ is the density of the dosimeter $\left(\mathrm{gcm}^{-3}\right), \mathrm{D}$ is the absorbed dose (Gy). Using the dye concentration in mol/ $\mathrm{L}$ and the average value of $\mathrm{A}_{0} / \mathrm{b}$, the molar extinction coefficient had been found to be $71625.1 \mathrm{Lmol}^{-1} \mathrm{~cm}^{-1}$ for NR films. 
Using the density of NR/ PVA to calculate the G-value in terms of $\mu \mathrm{mol} / \mathrm{J}$. The calculated G-value for these films and the concentration of the dye inside the films matrix were given in Table 1. Table 1. shows that it could be noticed that the G-value increases with the increase of the dye concentration. This may be due to the number of radiolysis products of NR/ PVA. This result reflects the important role of the polymer matrix in the bleaching process.

TABLE 1. The calculated G-value for NR/ PVA at different dye concentrations.

\begin{tabular}{|c|c|}
\hline Dye Con. $\mathbf{P h r}$ & G-value (NR/ PVA), $\boldsymbol{\mu m o l} / \mathbf{J}$ \\
\hline 0.2 & 0.0088 \\
\hline 0.4 & 0.0123 \\
\hline 0.5 & 0.0178 \\
\hline
\end{tabular}

\section{NR-gelatine gel}

The molar extinction coefficient of NR had been found to be $1.71004 \times 10^{5}$ $\mathrm{Lmol}^{-1} \mathrm{~cm}^{-1}$. The radiation chemical yield was calculated from the linear portion of the response curve ( $\Delta A$ vs. dose). Table 2. shows the calculated G-value for (NR-gelatine) gel at different dye concentrations. From these calculated data the G-value of (NR-gelatine) gel increases with increasing NR concentration.

TABLE 2. The calculated G-value for NR-gelatine gel at different dye concentrations.

\begin{tabular}{|c|c|}
\hline $\mathrm{NR}, \mu \mathrm{mol} / \mathrm{L}^{-1}$ & G-value (NR-gelatine) gel, $\mu \mathrm{mol} / \mathrm{J}$ \\
\hline 3.44 & 1.38 \\
\hline 5.6 & 1.59 \\
\hline 10.5 & 1.73 \\
\hline
\end{tabular}

\section{Pre-irradiation and post irradiation stability}

Both films $(0.5 \mathrm{phr})$ and gel $\left(5.6 \mathrm{~mol} / \mathrm{L}^{-1}\right)$ were tested by storing at $33 \%$ R.h. in room temperature $\left(25^{\circ} \mathrm{C} \pm 1\right)$ in diurnal cycles of day light. Both films and gels were stored one month before testing. The absorbance at 485 for films and 480nm for 30 days has been monitored. Fig. 5 \& Fig. 6. show excellent stability for both films and gel before and after irradiation.

Egypt. J. Rad. Sci. Applic., Vol. 29, No. 1-2 (2016) 


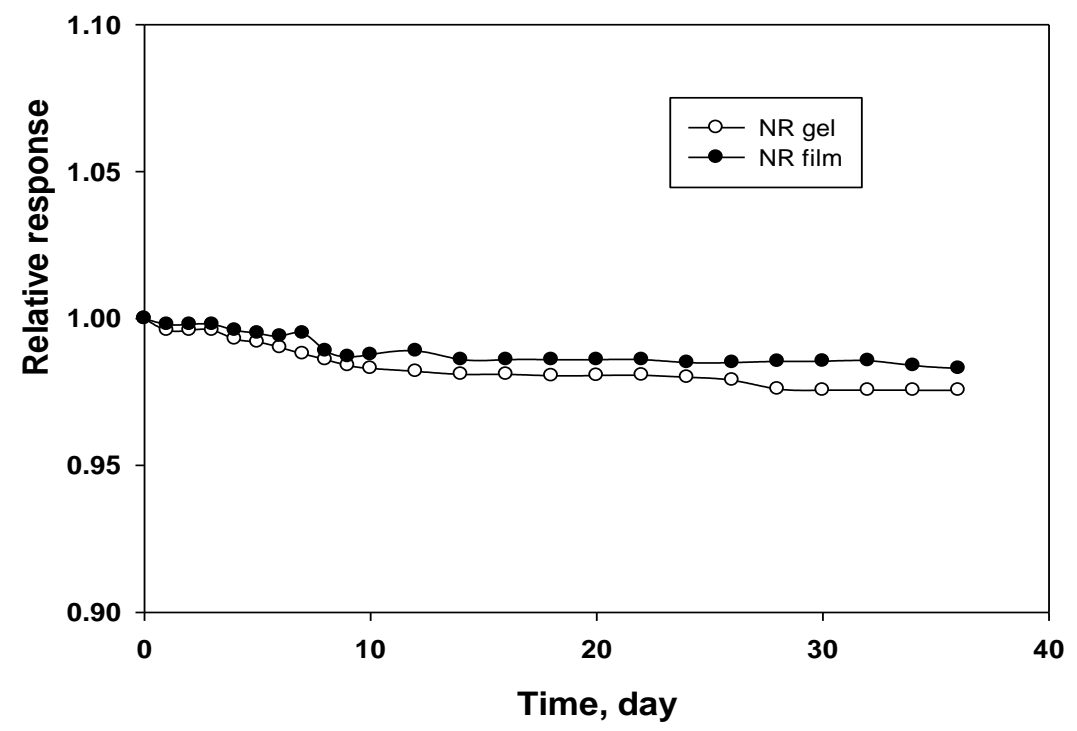

Fig. 5. Pre-irradiation stability of both NR-film and NR-gel stored under diurnal cycles of daylight.

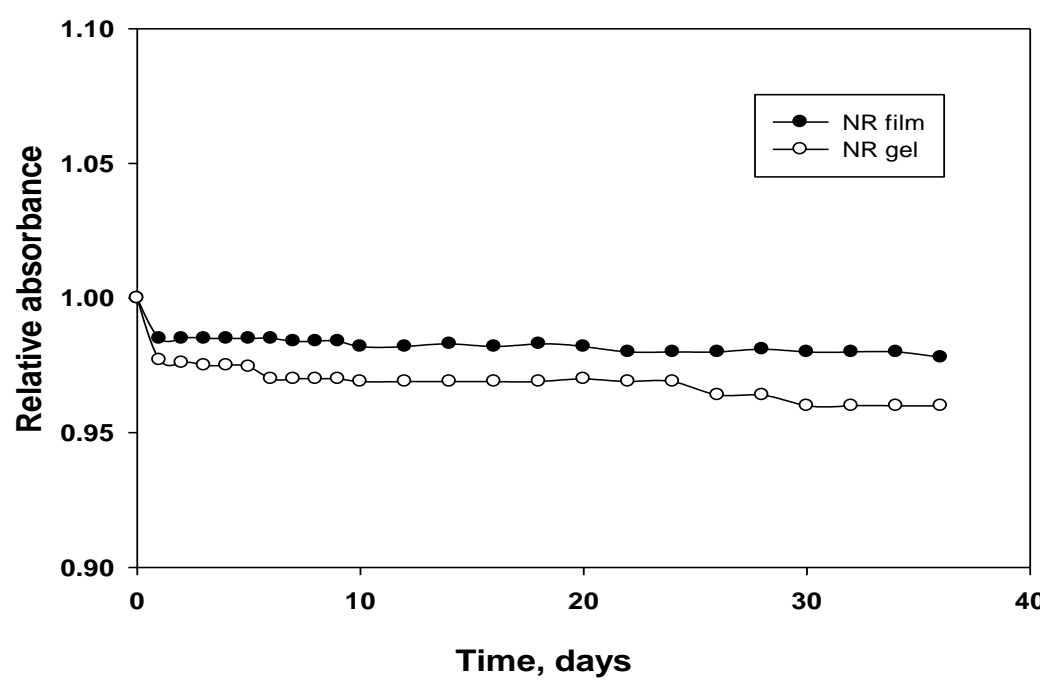

Fig. 6. Post-irradiation stability of NR-films and gel stored under diurnal Cycles of day light (irradiation dose $25 \mathrm{kGy}$ for films and 300Gy for gel).

Table 3. shows a comparison between different prepared dosimetry systems using the same dye that revealed the effect of substrate on the response sensitivity and dose range. Therefore, possible change in sensitivity of dyes to 
$\gamma$-photons for different irradiation purposes can be controlled throughout the preparation technique.

TABLE 3. Comparison between different dosimetry systems used for NR dye.

\begin{tabular}{|c|c|c|}
\hline System & Film & Solution \\
\hline Wavelength, nm & 485 & 480 \\
\hline Sensitivity & Sensitive & Higher sensitive \\
\hline Dose range & $(1-30)$ kGy & $(1-350)$ Gy \\
\hline Applications & $\begin{array}{c}\text { Food irradiation, } \\
\text { Medical sterilization, } \\
\text { Polymer crosslinking and } \\
\text { degradation. }\end{array}$ & $\begin{array}{c}\text { Food irradiation, } \\
\text { Water treatment and } \\
\text { Medical sterilization }\end{array}$ \\
\hline
\end{tabular}

\section{Conclusion}

Possible using the same dye NR in different dose ranges depends on the preparation techniques and the substrate used. The dye NR was prepared in both film and gel forms. Different dose ranges obtained depend on the sensitivity of the substrate, the film covers dose range from (1-30) kGy, the gel covers dose range (1-350) Gy. Both film and gel have excellent stability before and after irradiation.

\section{References}

Abdel-Fattah, A. A. and El-Kelany, M. (1998) Radiation sensitive indicators based on Bromophenol Blue and chloral hydrate dyed polyvinyl butyral. Radiat. Phys. Chem., 44, 317.

Abdel-Fattah, A. A., Hegazy, E. S. A. and Ezz El-Din, H. (2002) Radiation chemical formation of $\mathrm{HCl}$ in poly(vinyl butyral) films containing chloral hydrate for use in radiation dosimetry. Int. J. Polymeric Materials, 51, 413.

Ebraheem, S. and Beshir, W. B. (2007). Investigation of dyed film based on 2, 6dichlorophenol dyed poly (vinyl alcohol) and poly (vinylbutyral) for possible use in high-dose processing dosimetery. Arab J. Nucl. Sci. Applic., 38, 1.

El-Kelany, M. (2011) Coloured PVA film containing trypane blue for dosimetric applications. Arab. J. Nucl. Sci. Applic., 36, 7.

Soliman, Y. S. (2005) Development of some polymeric materials for possible use as radiation dosimetry system. M.Sc. Thesis, Chemistry DepT., Faculty of Science, Beni-Suef Branch, Cairo University, p 53.

(Received: 21/01/2016;

accepted: 03/04/2016)

Egypt. J. Rad. Sci. Applic., Vol. 29, No. 1-2 (2016) 


\section{دراسـة مقارنــة فيزيائيـة لصـبغة الأحمـر المتعــادل المحضـرة بطرق مختلفة لقياس الجرعات الإشعاعية المنخفضة لإنة \\ عصام فهيم ، و مثيرة الكيلانى

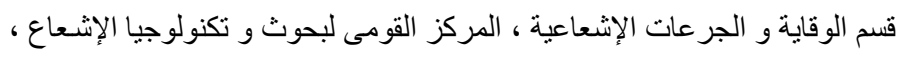

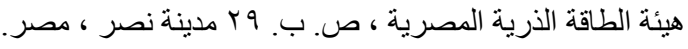

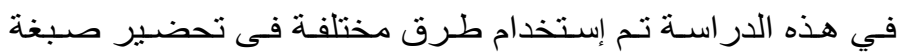

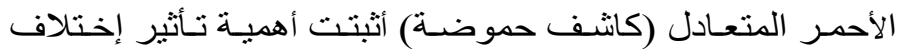

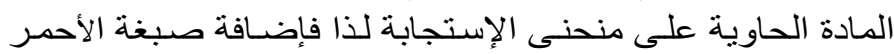

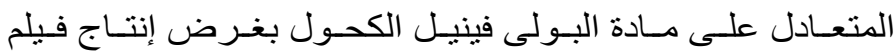

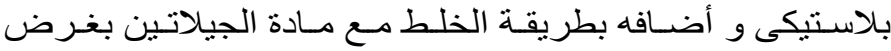

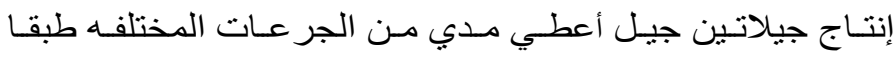

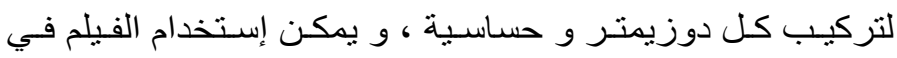

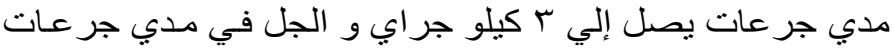

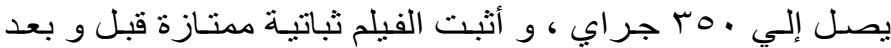

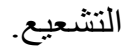

Egypt. J. Rad. Sci. Applic., Vol. 29, No. 1-2 (2016) 